ارزيابى جند عصارهگير براى تعيين آهن قابل استفاده ذرت (Zea mays L.) و حد بحرانى آن در تعدادى از خاكهاى آهكى

\author{
حميدرضا متقيان"، مرتضى شيرمحمدى و عليرضا حسين يور'

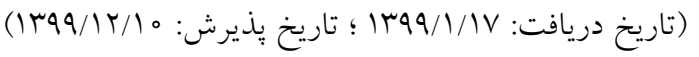

جكيده

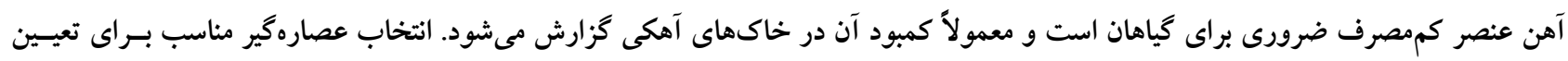

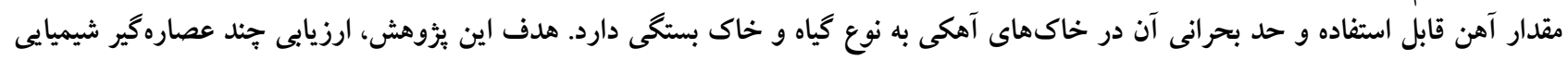

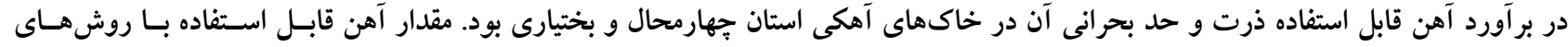

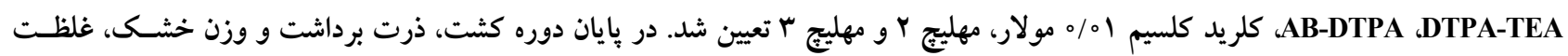

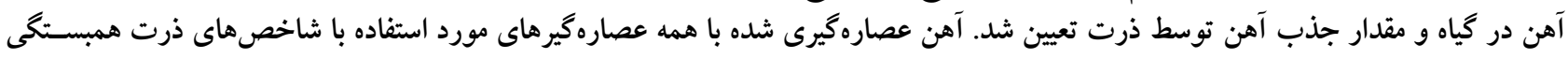

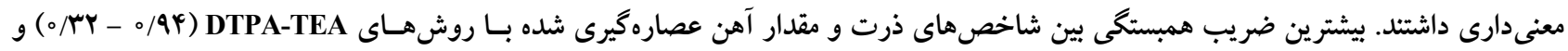

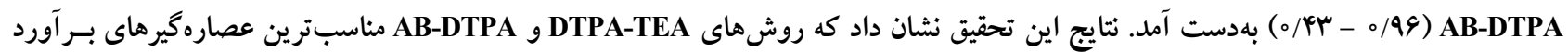

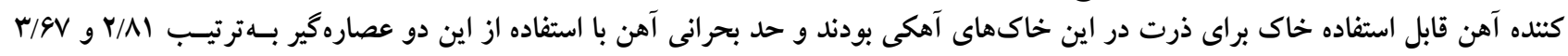

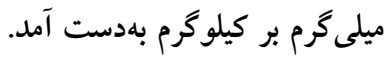

وازههاى كليدى: آهن قابل استفاده، حد بحرانى، ذرت، عصارهگير شيميايى 
باشد. براى ارزيابى توانايى عصارهذيرهـاى مختلـفـ در بـرآورد

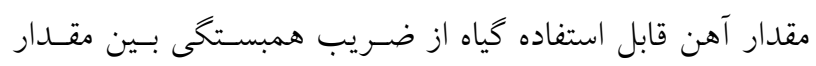

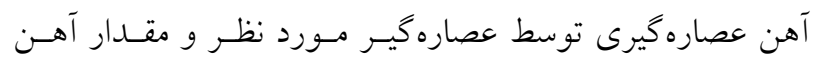
جذب شده توسط كياه استفاده مى عشود (ه) (ه).

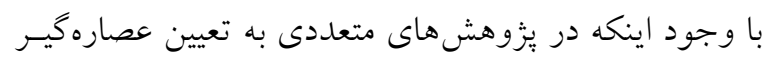

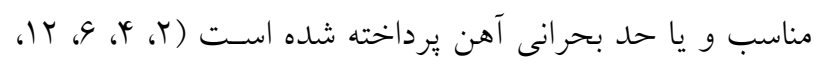

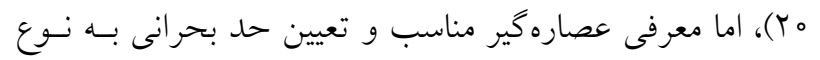

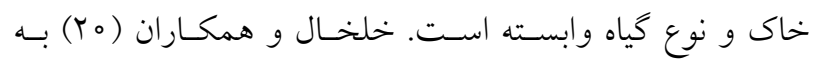
ارزيابى روش هاى مختلف عصاره گيرى آهن قابل استفاده كيـاه

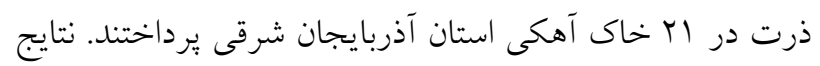

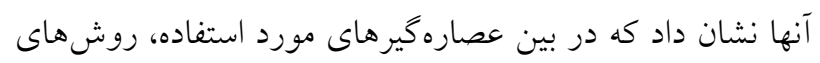

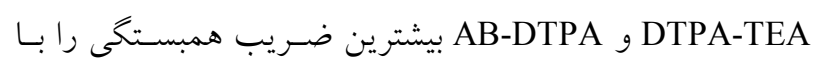

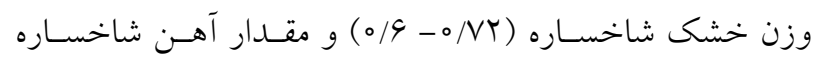

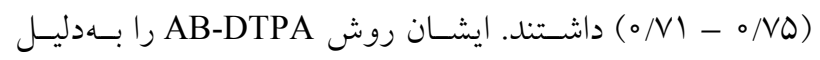

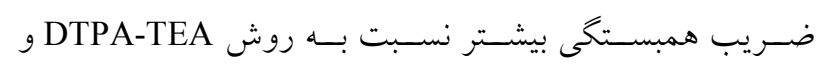

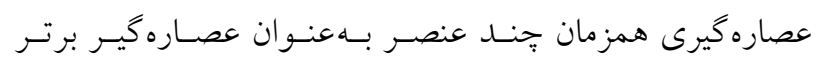

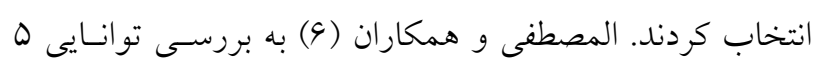
روش عصاره گيرى شيميايى در برآورد آهن قابـل استـفاده كيـاه

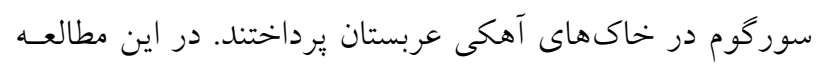

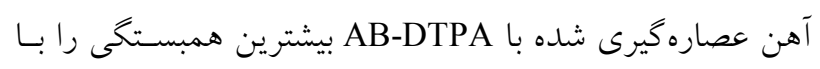

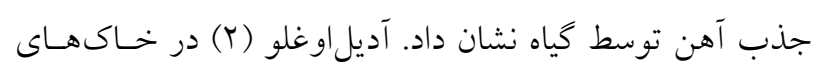

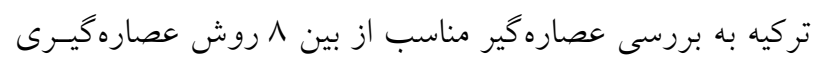

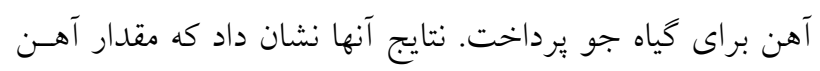

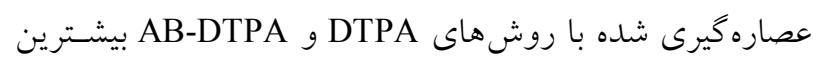

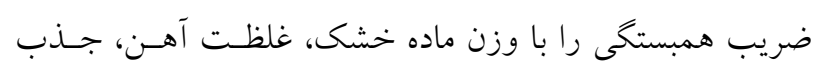

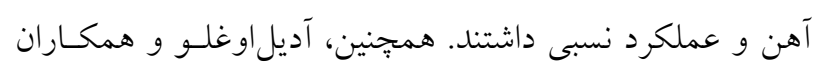

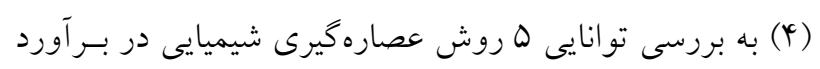

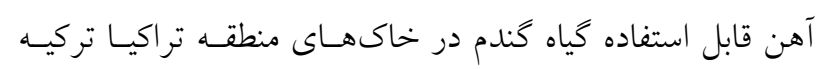

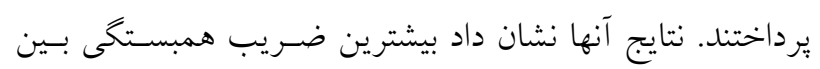

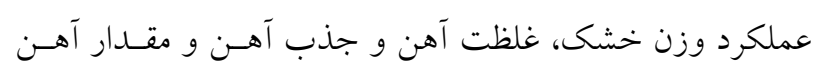

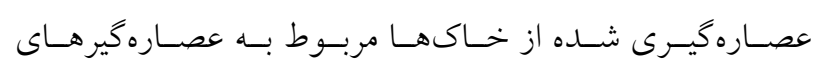

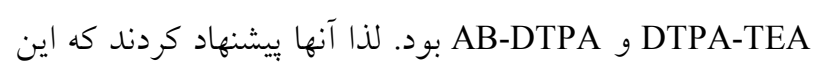

آهن بيشتر از ساير عناصر كممصرف بـراى كياهـان مـورد نيـاز

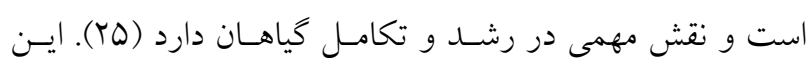

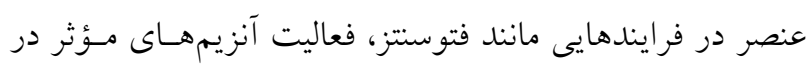

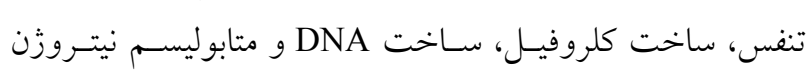

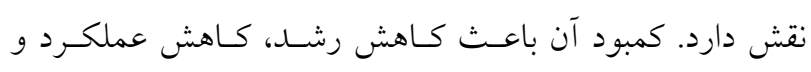

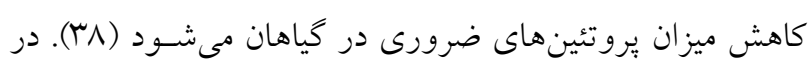

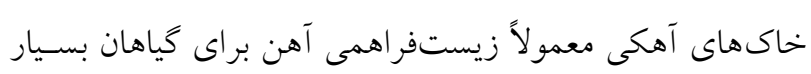

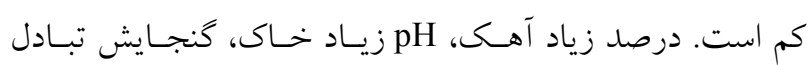

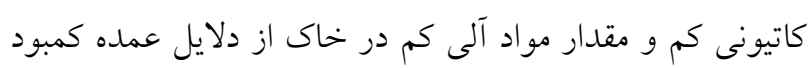

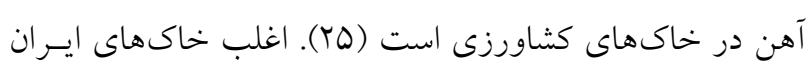

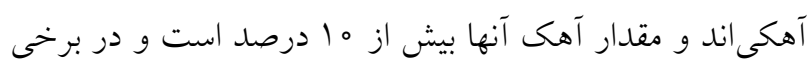

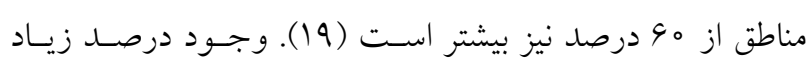

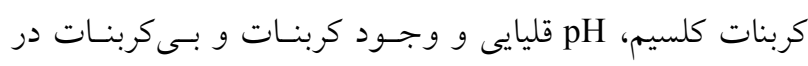
آبهاى آبيارى خاكهاى آهكى ايران باعث شده تا كمبود آهـن

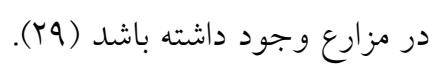

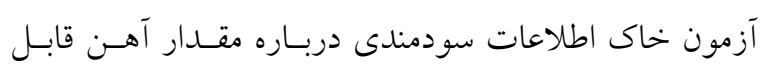

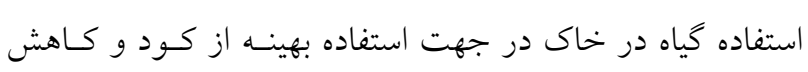
آسيب كمبود آهن ارائه مى كند. براى تعيين مقدار قابـل استتفاده

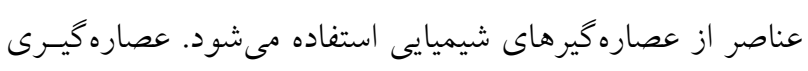
روش هاى شيميايى هستند كه عنصر غذايى قابل استفاده گياه بـا

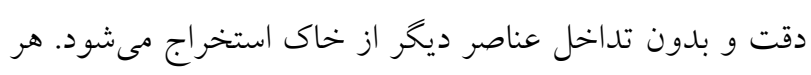

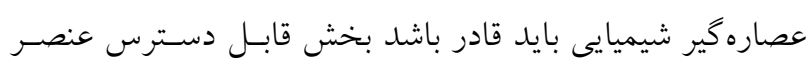

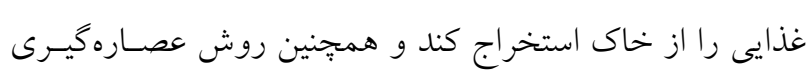

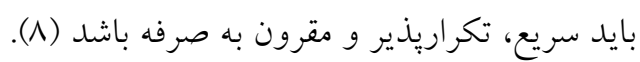

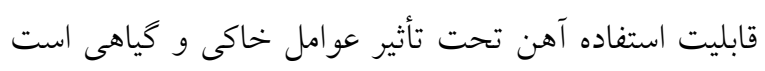

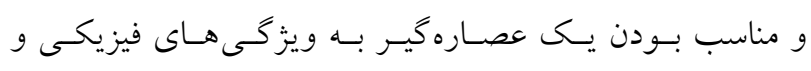

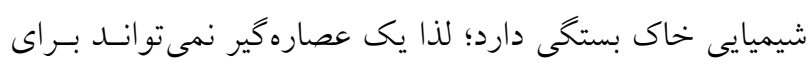

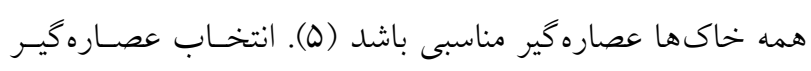

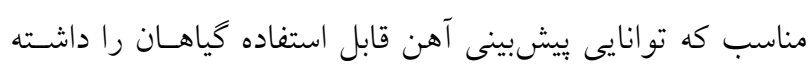

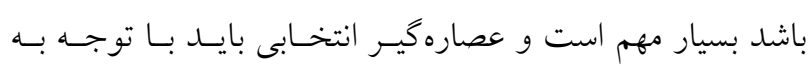

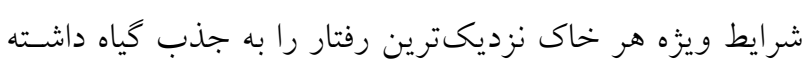




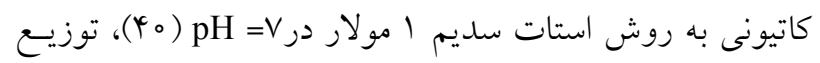

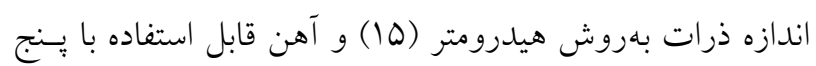
روش عصارهگيرى شيميايى (جدول () تعيين شد.

\section{كثت گُلخانهاى}

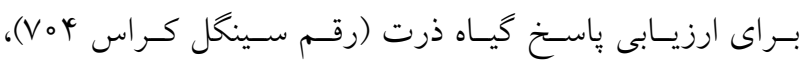

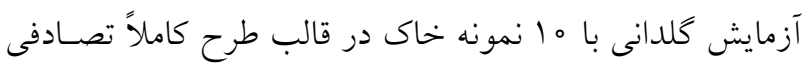

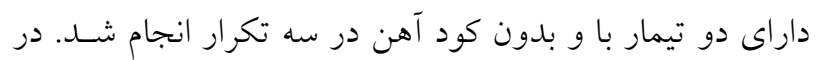

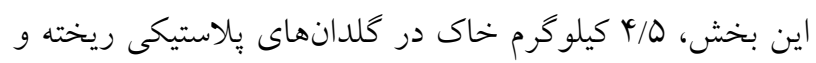

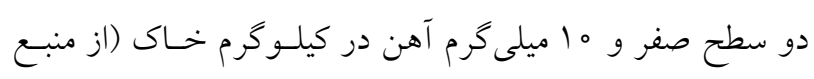

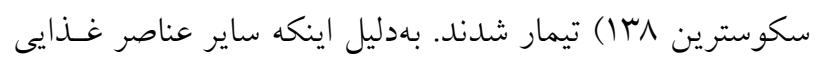

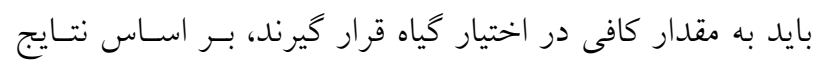

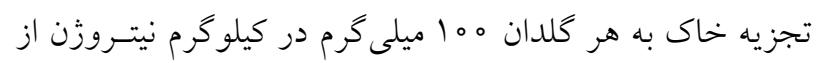

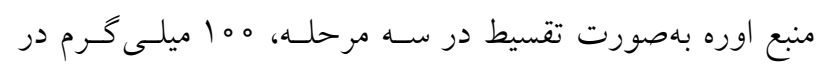

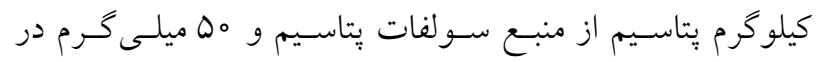

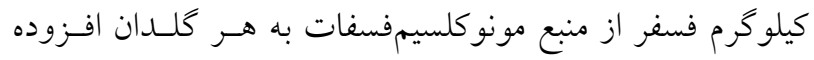

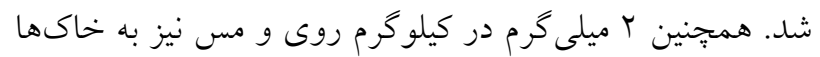

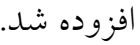

براى كشت كيـاه، بـــرهاى ذرت درون آب قـرار داده و در

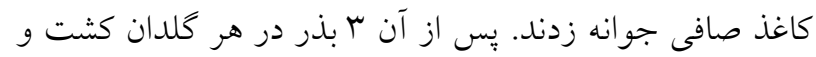

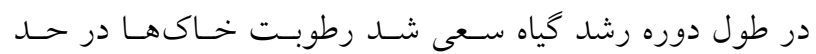
ظرفيت مزرعه ثابت نكحداشته شـود. بــراى ايـن منظـور، مقــدار

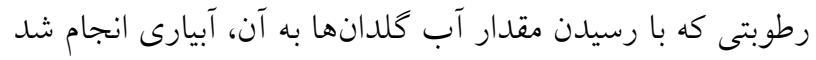

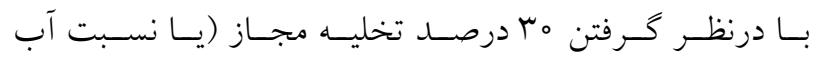

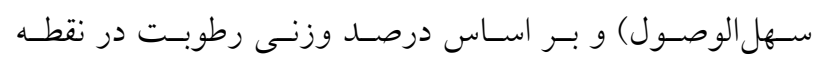

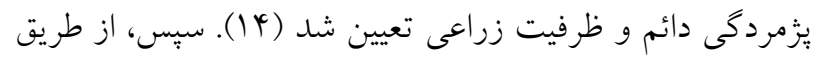

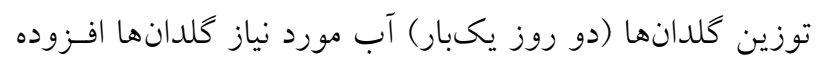

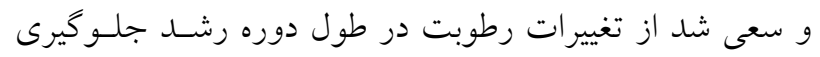

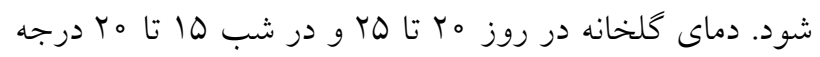

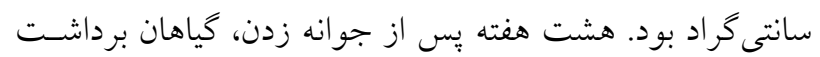

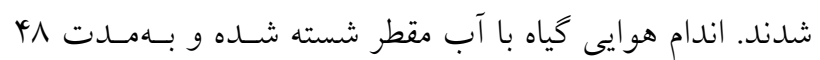

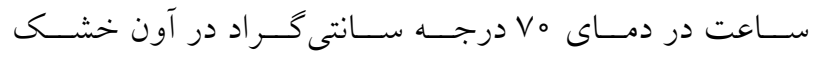

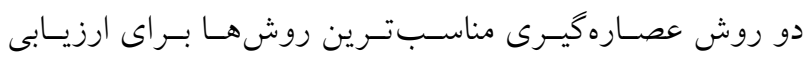

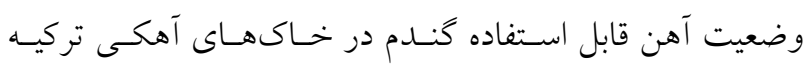

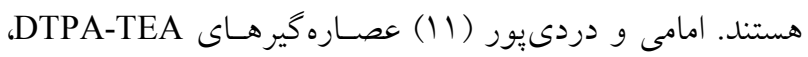

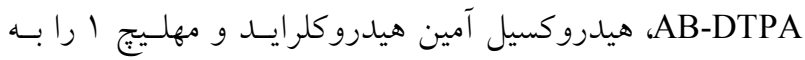

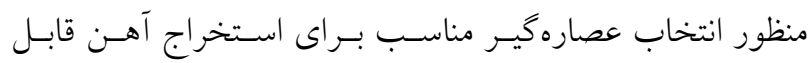

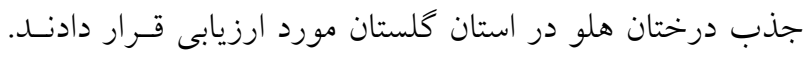

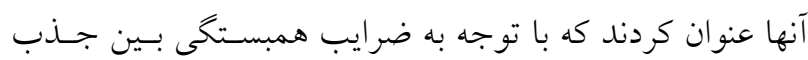

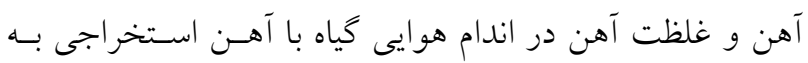

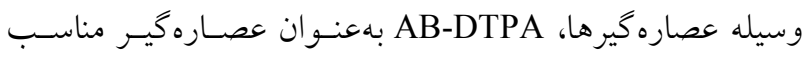

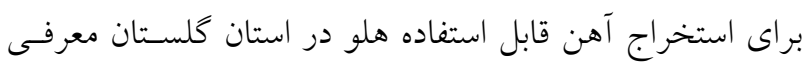
مىشود. ذرت در ايران از نظر كل سطح برداشت غلات بعد از كندم،

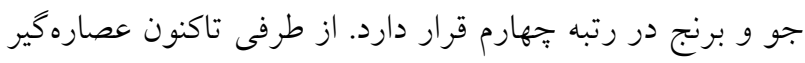

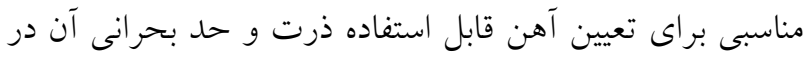
خاكهاى اسـتان جهارمحسال و بختيـارى معرفى نشــده اسـت.

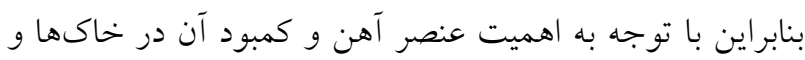

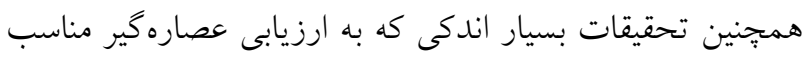

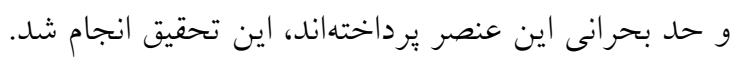

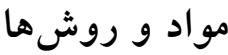
خصوصيات فيزيكى و شيميايى خاكها

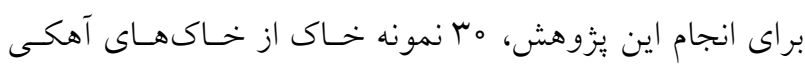

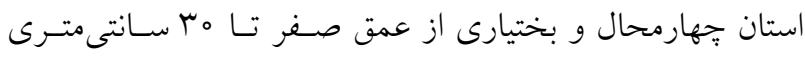

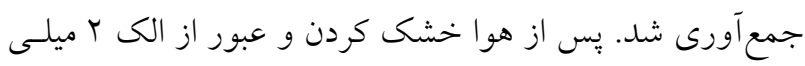

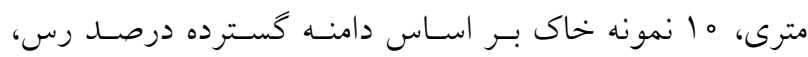

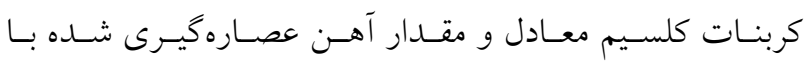

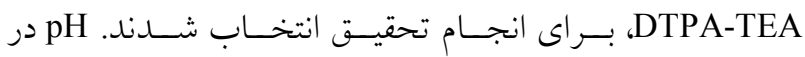

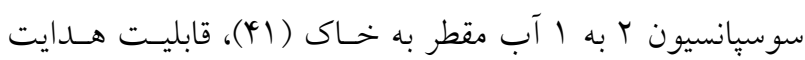
الكتريكى در عصاره صاف شده سوسِانسيونهاى با نسبت ب بـه.

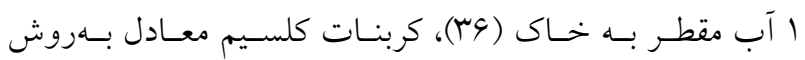

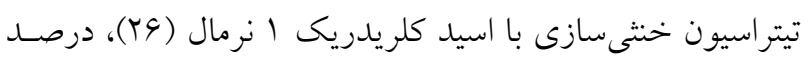

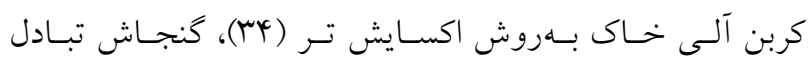


جدول ا. روشهاى عصارهگيرى شيميايى مورد استفاده در تعيين آهن قابل استفاده

\begin{tabular}{|c|c|c|c|c|}
\hline منبع & زمان تكان & 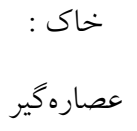 & تركيب عصارهگير & عصاره كير \\
\hline ry & rro & $1: Y$ & 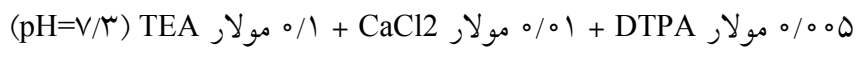 & DTPA-TEA \\
\hline rq & 10 & $1: r$ & 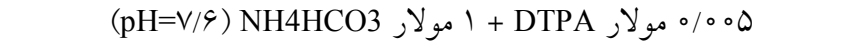 & AB-DTPA \\
\hline$r_{\circ}$ & Q & $1: 10$ & 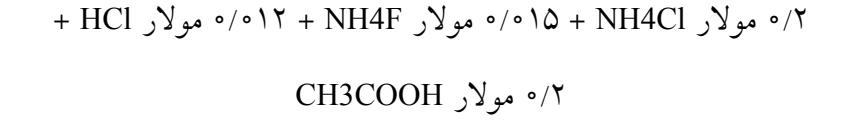 & مهليج r \\
\hline 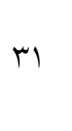 & Q & $1: 10$ & 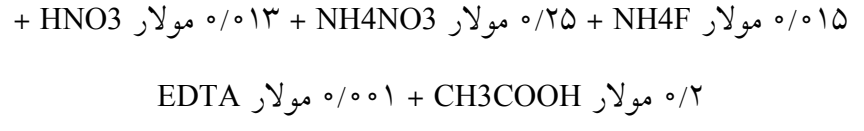 & مهليج ب مب \\
\hline 11 & kro & $1: 10$ & إم/ مولار CaCl2 & 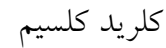 \\
\hline
\end{tabular}

مطالعه با استفاده از روش ميجريخ با درنظر كرفتن عملكـرد نسبى هم درصد تعيين شد (1). $\log (100-y)=2-C x$ كه در آن y عملكرد نسبى (درصد)، C ضريب متغير و X مقــدار آهن عصاره گيرى شده با روشهاى مختلف است.

\section{نتايج و بحث} ويزّگى هاى خاكهاى مورد مطالعه نتايج تجزيه فيزيكى و شيميايى خاكهــا در جـدول r آورده شده است. بر اساس اين نتايج، pH خاكها در دامنه V/O تـا

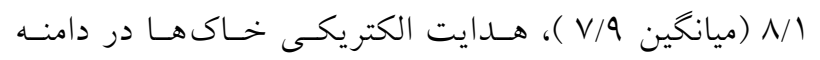

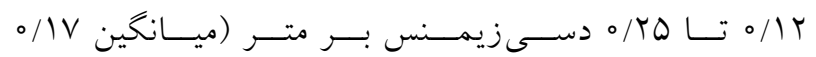
دسى زيمنس بر متر) و مقدار كربنات كلسيم معادل خـاكهـا در دامنه r/Iا تا ال| درصد (ميانخين rV/D درصد) بهدسـت آمد. همجهنين دامنه تغييرات مقدار رس خـاكهـا هب تـا هD

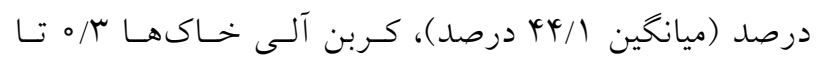

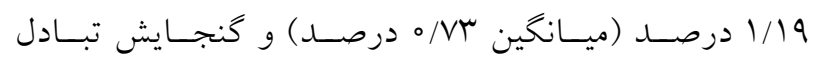

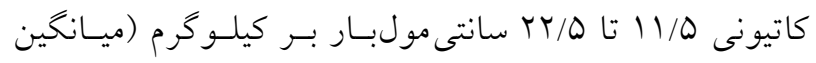

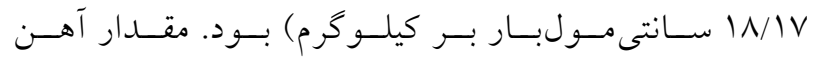

و وزن خشى اندام هوايى اندازهگيرى شد. غلظت آهن در اندام هوايى بـا روش خاكسـتر خشـى (9) و بــا اسـتفاده از دسـتخاه

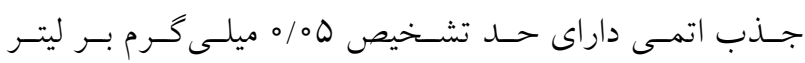
ساخت استراليا) تعيين و آهن جذب شـــ GBC, 932) اندام هوايى از طريق رابطه زير محاسبه شد: عملكرد خشك (كيلـو گرم در گلـدان) × غلظـت آهـن

(ميلى گرم در كيلوگرم) = جذب آهن (ميلى گرم در كلدان)

تجزيه و تحليل آمارى

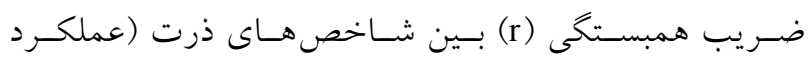
خشك، غلظت آهن و جذب ) و مقــدار آهـن قابـل اسـتفاده خاى تعيين و عصاره گير يا عصارهذيرهاى مناسب بر اسـاس معنى دار بودن ضرايب همبستخى انتخاب شدند. براى مقايسه

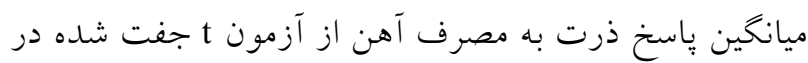
سطح احتمال ه درصد و نرمافزار Statistica استفاده شـــ.

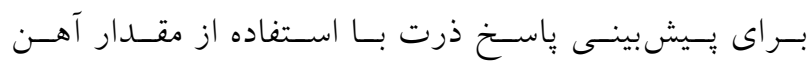
عصاره گيرى شده و خصوصيات خاكهاى مـورد مطالعسه، از

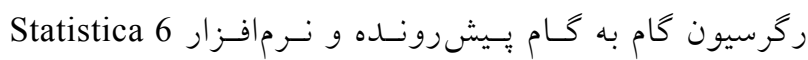
استفاده شد. همجنين حد بحرانى آهن در خـاك هــاى مـورد 
جدول r. برخى ويزّى هاى فيزيكى و شيميايى خاكهاى مورد مطالعه

\begin{tabular}{|c|c|c|c|c|c|c|c|c|}
\hline آهن قابل & كنجايش تبادل & هدايت الكتريكى & $\mathrm{pH}$ & كربن & كربنات كلسيم & سيلت & رس & \multirow[t]{2}{*}{ شماره خاك } \\
\hline$\left(\mathrm{mg} \mathrm{kg}^{-1}\right)$ & $\left(\mathrm{cmolc} \mathrm{kg}^{-1}\right)$ & $\left(\mathrm{dS} \mathrm{m} \mathrm{m}^{-1}\right)$ & \multicolumn{5}{|c|}{$(\%)$} & \\
\hline$Y / \Lambda \Lambda$ & $r \circ / 9$ & $\circ / \mu$ & $\mathrm{V} / \mathrm{\Lambda}$ & $\circ / N Y$ & TA/V & ro & $\Delta \Delta$ & 1 \\
\hline$T / 10$ & $19 / \mu$ & $\circ / 1 \mu$ & $\Lambda / 1$ & $\circ / \mu_{0}$ & $\mathrm{rQ} / \mathrm{s}$ & ky & $\Delta r$ & r \\
\hline$\varphi / \wedge 。$ & $r Y / D$ & $0 / 1 Y$ & $V / 9$ &.$/ 01$ & $r q / 4$ & rq & $4 q$ & r \\
\hline $1 / 40$ & $Y 1 / 9$ &.$/ 14$ & $V / \Lambda$ & $\circ / V_{1}$ & $r \varphi / 4$ & Kr & 14 & q \\
\hline $1 / 19$ & $19 / 0$ & $\circ / 1 \mu$ & $\Lambda / 1$ &.$/ D Y$ & $r Y / T$ & Fr & 41 & 0 \\
\hline$r / 9 V$ & $10 / 9$ & $0 / 19$ & $V / 9$ & $\circ / \Lambda \circ$ & $r$ r/d & ky & rv & 9 \\
\hline$\varphi / D_{0}$ & $11 / 0$ & $0 / T 1$ & $\mathrm{~V} / \mathrm{V}$ & $\circ / 4 V$ & $41 / 0$ & س & rQ & V \\
\hline $9 / \pi^{\circ}$ & $1 V / 9$ & $O / Y Y$ & $\Lambda / 1$ & $1 / 19$ & $T \mu / l$ & $\Delta \Delta$ & ऍ & $\wedge$ \\
\hline $1 / N 0$ & $1 / / 0$ & $0 / T Q$ & $\mathrm{~V} / \mathrm{\Lambda}$ & $1 / 19$ & $11 / \mu$ & 49 & $\uparrow \wedge$ & 9 \\
\hline $\mathrm{Q} / \mathrm{\Lambda}$ & $1 V / 9$ & $0 / T \mu$ & $V / 9$ &.$/ 9 V$ & $14 / 1$ & 49 & $4 q$ & 10 \\
\hline $01 / 1$ & $18 / 9$ & $\mu_{\circ} / l$ & $10 / 0$ & $\varphi / 0$ & 要 & $1 \pi / r$ & $r \circ / \varphi$ & ضريب تغييرات (CV) \\
\hline
\end{tabular}

كالات كننده هستند كه بسته به روش عصارهگيرى مورد اسـتفاده مقدار متفاوت آهن قابل استفاده را استخراج مى كنــــ. اسـتخراج مقدار آهن قابل استفاده بيشتر توسط عصارهگير مهليج ب نسـبت به ساير روشها مىتواند بهدليل وجود اسيدهاى رقيق و كـلات كنــده اتسيلن دى آمسين تــــاس اسـتيك اسـيد (EDTA) در ايسن

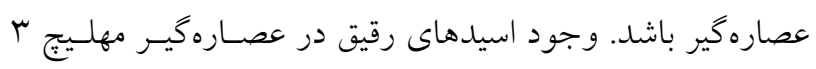
باعث افزايش فعاليت عناصر كـمـمصرف در فـاز محلـول شـــه بهدليل انحلال كربناتها و حضور كلات كننده (EDTA) باعث

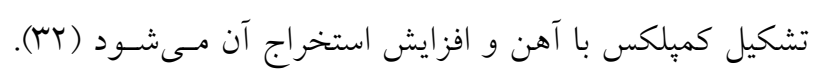

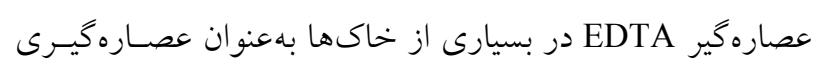
موفق براى عناصر كممصرف كاتيونى معرفى شـده اسـت (YT).

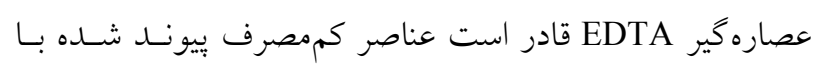
اكسيدها، مواد آلى و بخشى از عناصر موجود در كانىهاى رسى ديى

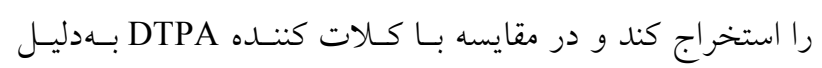
داشتن pH كمتر مقدار بيشترى از عناصـر كـممصـرف خـاك را

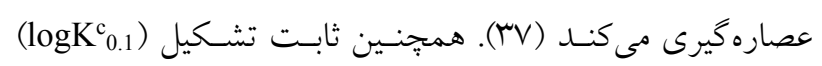
در $\mathrm{Fe}(\mathrm{III})+\mathrm{L} \rightleftharpoons \mathrm{FeOHL}+\mathrm{H}^{+}$ واك
عصاره گيرى شده بـا روش DTPA-TEA در دامنسه 91 دا تـا 9/Y。 ميلى گرم در كيلو گرم قرار داشت. مقدار آهن عصارهگيرى شده بهروش هاى مختلف در جدول

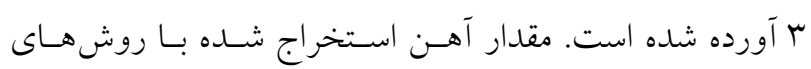
مختلـف در يـك خـاك متفـاوت بـهدسـت آمـد كـه ايسن امـر

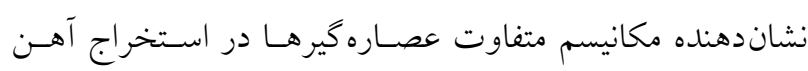
است. شرايط مختلف عصاره گيرها مانند نسبت محلول به خاك، محلول، مدت زمان عصاره گيرى و نوع شكل استخراج شده

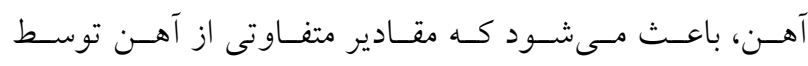
عصاره گيرها استخراج شود. در هر عصارهذيـر نيـز مقـدار آهـن عصاره گيرى شده در خاكها اخـتلاف زيـادى داشـت كـه ايسن مسئله مىتو اند بهدليل ويزگى هاى متفاوت خاكها و تفـاوت در

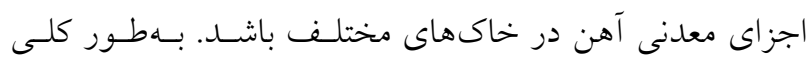

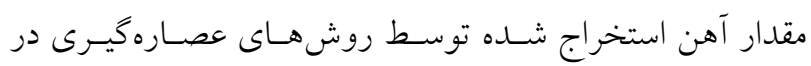
خاكهاى مورد مطالعه بهصورت زير بود: مهليج > DTPA-TEA > AB-DTPA > مهليج r > كلريد كلسيم عصاره گيرهاى مختلف شامل اسيدهاى رقيق، نمكىها يا عوامـل 
جدول r. مقدار آهن استخراج شده (ميلى گرم در كيلوگرم) توسط عصارهگيرهاى مختلف در خاكهاى مورد مطالعه

\begin{tabular}{|c|c|c|c|c|c|}
\hline كلريد كلسيم & مهليج r & مهليج & AB-DTPA & DTPA-TEA & شماره خاى \\
\hline$\circ / Y_{0}$ & $9 / 01$ & $1 / Y \Lambda$ & $Q / r V$ & $Y / \Lambda \Lambda$ & 1 \\
\hline$\circ / 1 \wedge$ & س//ه & $0 / 91$ & $r / 91$ & $T / 10$ & $r$ \\
\hline $0 / \mu_{Y}$ & $1 / 90$ & $1 / \mathrm{VV}$ & $9 / r_{0}$ & $\psi / \Lambda 0$ & $r$ \\
\hline $0 / 1 Y$ & $\varphi / \Lambda 。$ & $\circ / \mathrm{VA}$ & $1 / 91$ & $1 / 40$ & $r$ \\
\hline $0 / 19$ & $r / 91$ & $0 / 94$ & $1 / 91$ & $1 / 19$ & 0 \\
\hline$\circ / 4 \wedge$ & $Q / Y Y$ & $1 / 79$ & $\varphi / 4 \wedge$ & $r / 9 V$ & 9 \\
\hline $0 / \mathrm{V}$ & $9 / 10$ & $1 / N 0$ & $9 / 19$ & $\varphi / \Delta \circ$ & V \\
\hline سא/ & N/A & $1 / K T$ & $9 / 90$ & $9 / T_{0}$ & $\wedge$ \\
\hline$\circ / 11$ & YNQ &.$/ 40$ & $r / T q$ & $1 / V 0$ & 9 \\
\hline.$/ 90$ & $\Lambda / \Lambda \Lambda$ & $\mid / N 1$ & $9 / 19$ & $\Delta / \Lambda \Lambda$ & 10 \\
\hline $0 / 7 q$ & $4 / 40$ & $1 / 10$ & $\varphi / 4 \Delta$ & r/99 & ميانگين \\
\hline
\end{tabular}

موفق بود. هاينس و سـوئيفت (IV) گـزارش كردنــ كـه روش AB-DTPA بهطور قابل ملاحظهاى مقدار آهن بيشـترى نسـبت به روش DTPA-TEA عصاره کيرى مى كند. روش عصارهگيـرى كلريد كلسيم 1ه/ أمولار كمترين مقدار آهـن را عصـاره كيـرى كرد. كلريد كلسيم اه/ه مولار آهن تبادلى را از طريق جانشـينى استخراج مسى كنـــ. بــراى تعيـين مقـــار آهـن قابـل اسـتفاده در خاكهاى قليايى روش هاى اسيد و نمكى (مانند كلريــ كلسـيم) بهخاطر استخراج كمترين مقدار آهن مناسب نيستند و استفاده از روشهاى كلات و كلات بهعلاوه نمك در ايسن نـوع خـاكهـا بيشنهاد مىشود (r) (r).

\section{شاخص هاى گياه ذرت}

شاخص هاى كياه ذرت در ما خاك مورد مطالعـه در جــدول †

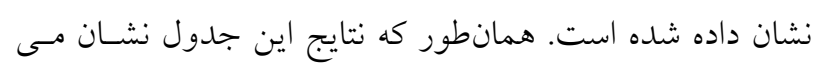
دهد كاربرد ه ا ميلى گرم آهن در كيلو گرم خاك باعـث افـزايش معنى دار وزن خشك گياه، جذب كل آهن و غلظت آهن در كياه شد. نتايج مشابهى توسط نبوىمقدم و همكاران (سM) و اتينگ و همكاران (TI) مشاهده شده است. نبوىمقدم و همكـاران (سب)

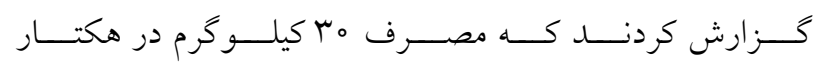

حضور EDTA برابـر بـا D/NQ و در حضـور DTPA برابـر بـا

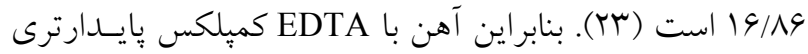
نسبت به DTPA تشكيل مىدهد (TY).

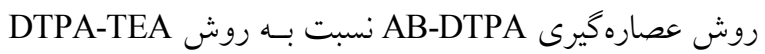
مقدار آهـن بيشـترى عصـاره گيـرى كـرد. روش عصـاره كيـرى AB-DTPA بى كربنات در اين عصاره گير منجر بـه تشـكيل كربنـات كلسـيم شده و از فعاليت كلسيم در محلـول كاسـته و بنـابراين تشـكيل كميلكس كلسيم - DTPA كاهش يافته و امكان ايجاد كميلكس

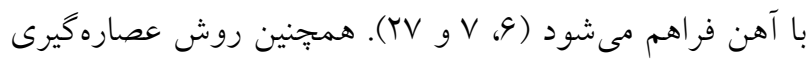
Dافر مار شده با استفاده از ترى اتانول آمين و همجينين محتوى كلريد كلسيم اه/ مولار اسـت كـه از حسل

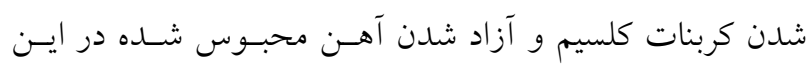
تركيب جلو گيرى مى كنند (YY). بهعلاوه يون NH4 ${ }^{+}$موجسود در روش AB-DTPA مىتواند جايخزين برخى كاتيونهـاى فلـزى شود (T). هاولين و سلطانيور (19) بهمنظور ارزيابى وضسعيت آهن خاكهاى كلرادو روش AB-DTPA را مورد آزمايش قـرار دادند و گزارش كردند كه عصارهگير AB-DTPA همانــد روش DTPA براى بيشبينى قابليت استفاده آهن در خاكهاى كلـرادو 
جدول f. شاخصهاى گياه ذرت در خاكهاى مورد مطالعه تحت تاثير كاربرد كود آهن

\begin{tabular}{|c|c|c|c|c|c|c|c|}
\hline \multirow{4}{*}{ عملكرد } & \multirow{2}{*}{\multicolumn{3}{|c|}{ 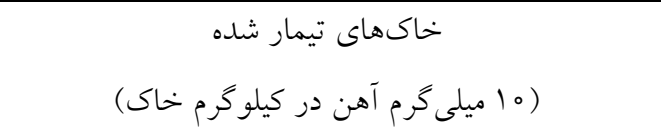 }} & \multirow{2}{*}{\multicolumn{3}{|c|}{ خاكهاى تيمار نشده }} & \multirow{4}{*}{ 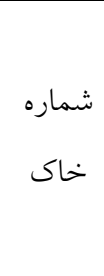 } \\
\hline & & & & & & & \\
\hline & جذب (ميلى گرم & ماده خشك & غلظت (ميلى كَرم & جذب(ميلى گرم & ماده خشك (كرم & غلظت (ميلى گرم & \\
\hline & در كلدان) & (خرم در گلدان) & در كيلوكرم) & در كلدان) & در كلدان) & در كيلو گرم) & \\
\hline $9 \mathrm{~V} / 00$ & F/YT & $11 / 00$ & HNF/Tr & $r / 90$ & $V / 4 \mid$ & $r \Delta T / r_{0}$ & 1 \\
\hline $9 Y / 00$ & T/9Y & $10 \% 0$ & rब9/10 & $1 / T V$ & 9109 & $r \circ q / I V$ & r \\
\hline$a r / \mu r$ & $r / \mu r$ & $11 / \pi \mu$ & r.r/l。 & T/AG & $10 / 0 r$ & $T V Y / 90$ & r \\
\hline $99 / \pi r$ & $1 / N^{4}$ & $9 / 09$ & $195 / 90$ & O/AT & $9 / \pi \mu$ & $\mid r q / \Delta r$ & r \\
\hline$N 4 / 99$ & $1 / \Gamma \Lambda$ & $V / 99$ & $191 / \% \circ$ & ס & $9 / 00$ & $\mid T V / \Lambda_{0}$ & 0 \\
\hline $99 / \pi r$ & $r / 0_{0}$ & r//1 & $r \circ q / \mu r$ & r/TO & $10 / 94$ & $r \mid Q / N T$ & 4 \\
\hline $9 \pi / \pi r$ & $r / T V$ & $1 r / 00$ & $M Y I / V V$ & $r / \Delta V$ & $11 / 99$ & $r \circ \varphi / \Delta r$ & v \\
\hline$M / \mu \pi$ & $Q / \circ V$ & $15 / 19$ & $r \wedge F / q r$ & $r / 0 r$ & $11 / 99$ & $M Y Q / A V$ & $\wedge$ \\
\hline$V \pi / \mu r$ & $T / 19$ & N/99 & $r \Delta \circ / I V$ & $0 / \Lambda 1$ & $9 / T_{4}$ & ITN/OV & 9 \\
\hline $9 Y / 00$ & $4 / Y 9$ & $1 \% / 00$ & MTV/G。 & $\circ / \mathrm{AV}$ & $\mid r / 00$ & MTY/OT & 10 \\
\hline $11 / 19$ & $r / r \Delta^{a}$ & $1 \circ / V^{a}$ & $r a Y / \Lambda \Lambda^{a}$ & $r / \mu_{\circ} \mathrm{b}$ & $N / q y^{c b}$ & $\left\langle\left\langle y / 0^{b}\right.\right.$ & ميانخين" \\
\hline
\end{tabular}

همبستخى بين شاخص هاى گياهى و مقدار آهن عصارهگيـرى

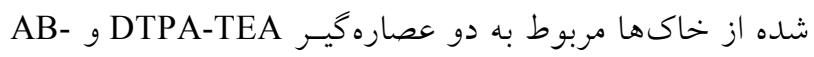

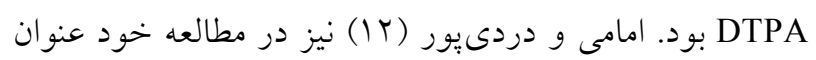

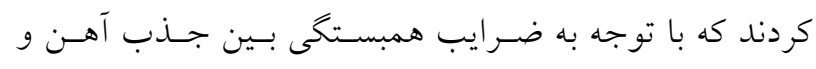

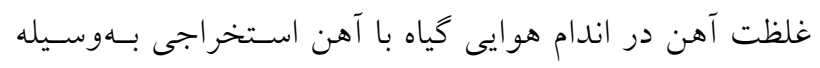

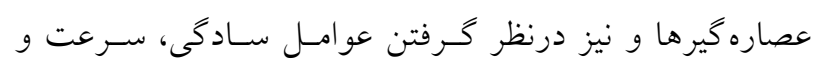

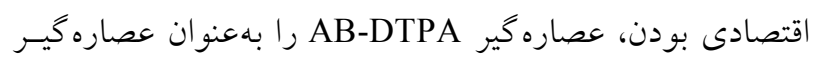
مناسب براى استخراج آهن قابل استفاده هلو در استان كلستان رئان

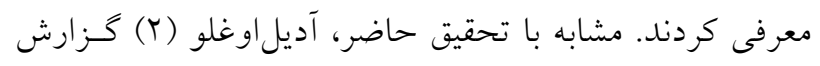

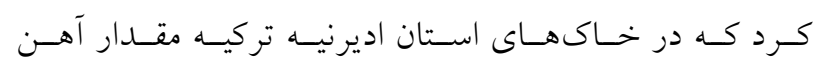

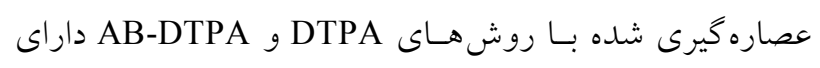

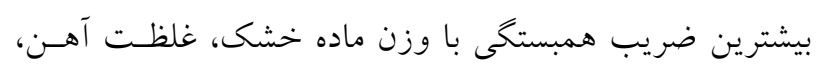

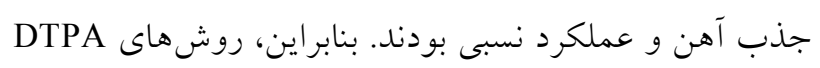

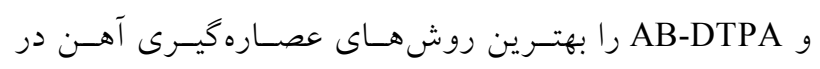

كود آهن (سولفات آهن) در خاكهاى استان خراسان جنـوبى

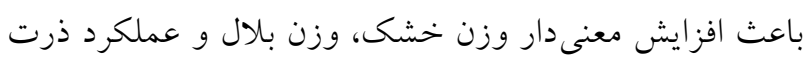

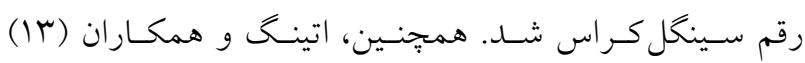

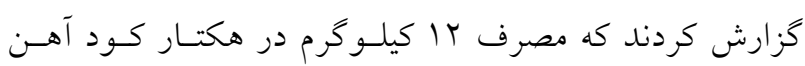

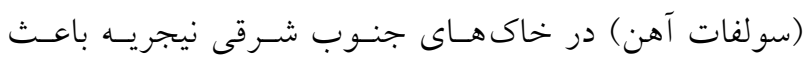

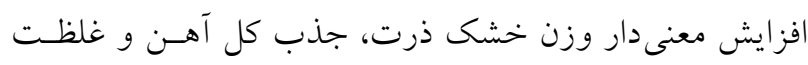
آهن در ذرت شد. ضريب همبستخى بين مقادير آهن عصـارهذيـرى شــده بـا روش هاى مختلف و شاخص هاى ذرت در جدول هـ نشان ندان داده

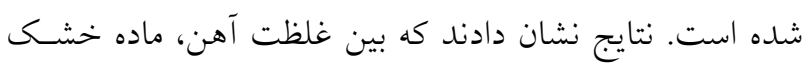

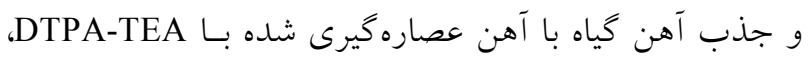
AB-DTPA

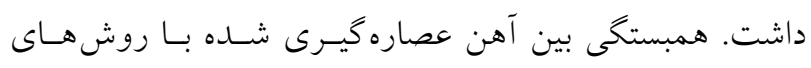

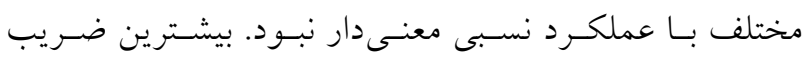


جدول ه. ضرايب همبستكى بين آهن استخراج شده از خاك توسط عصاره گيرها و شاخصهاى ذرت (م=10)

\begin{tabular}{|c|c|c|c|c|}
\hline عملكرد نسبى & ماده خشك & جذب آهن & غلظت آهن. & S \\
\hline$\circ / \Delta \mu^{\mathrm{ns}}$ & $\circ / \wedge \varphi^{* *}$ & $\circ / 9 V^{* *}$ &.$/ 9 Y^{* *}$ & AB-DTPA \\
\hline$\circ / \Delta \mu^{\mathrm{ns}}$ & $\circ / \Lambda \varphi^{* *}$ & $\circ / 9 V^{* *}$ & $\circ / 9 r^{* *}$ & DTPA-TEA \\
\hline$\circ / \Gamma \wedge^{\mathrm{ns}}$ & $\circ / 9 \mu^{*}$ & $\circ / \wedge Q^{* *}$ & $\circ / 9 r^{* * *}$ & مهليج r \\
\hline$\circ / \Delta \Lambda^{\mathrm{ns}}$ & $\circ / 9 \mu^{*}$ & $\circ / \mathrm{V} Q^{*}$ & $\circ / \Lambda I^{* *}$ & مهليج r \\
\hline$\circ / \Delta V^{n s}$ & $\circ / \partial \mathrm{rns}^{\mathrm{ns}}$ & $0 / 94^{*}$ & $\circ / \mathbb{Y} \wedge \wedge^{\mathrm{ns}}$ & كلريد كلسيم \\
\hline
\end{tabular}

** * و ns به ترتيب معنى دار در سطح احتمال ه درصد، ا درصد و عدم معنى دارى است.

خاكهاى مورد مطالعه گزارش كردند. بر خلاف ايسن نتسايج، حد بحرانى آهن

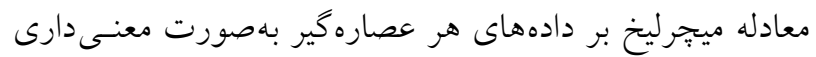

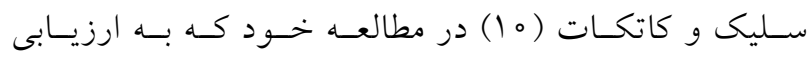

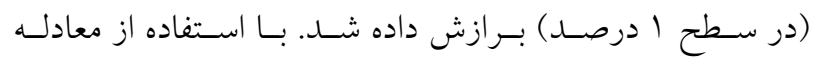
روش هاى عصاره گيرى شيميايى آهن قابل استفاده درختـان

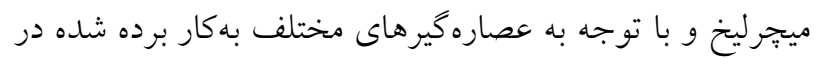

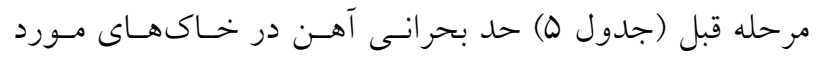

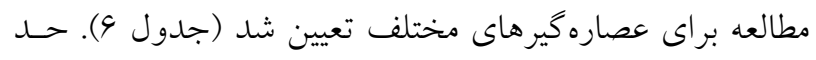

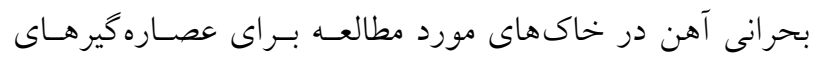

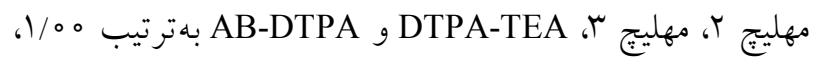

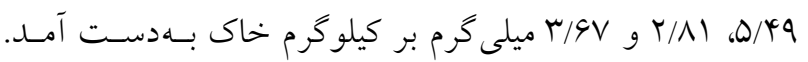

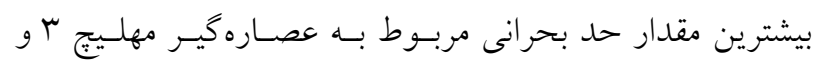

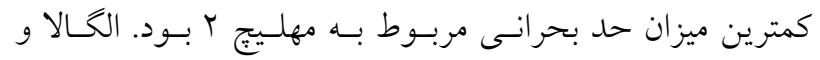

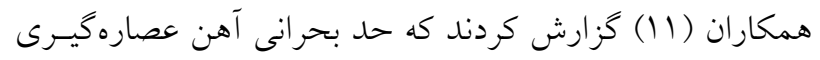

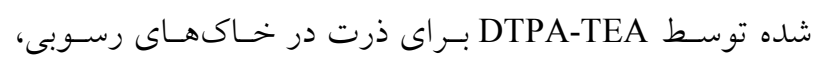

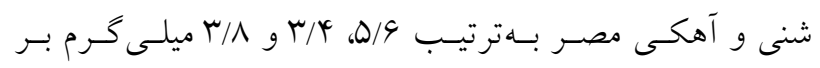

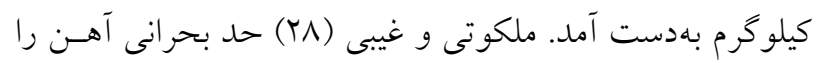

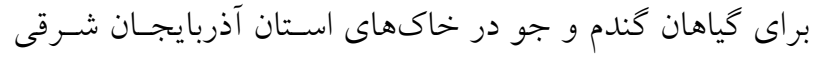

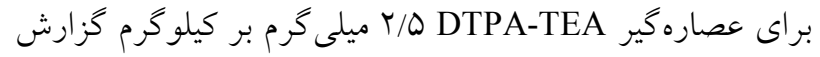

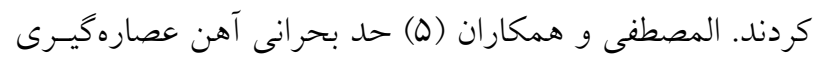
شده با AB-DTPA را در خاكهاى آهكى عربستان بـراى كيـاه

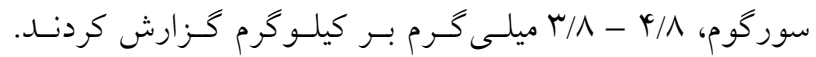
ويزگ هاى خاك از قبيل pH، كُنجايش تبـادل كـاتيونى، مقــدار

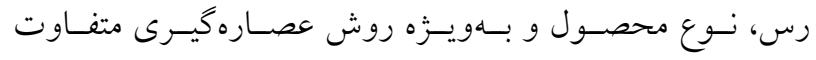

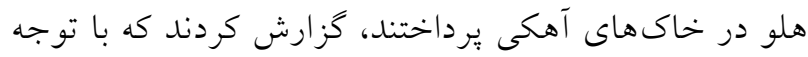
به ضريب همبستخى بين مقدار آهن بـركَهـا و مقــدار آهـن

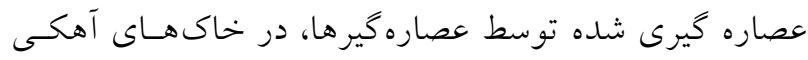
منطقه مورد مطالعه روش هاى عصاره خيـرى

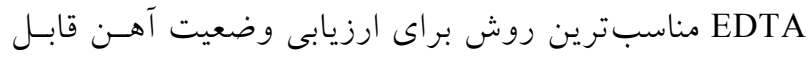

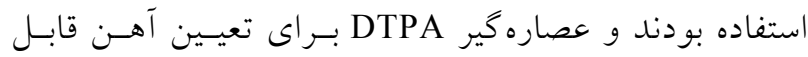

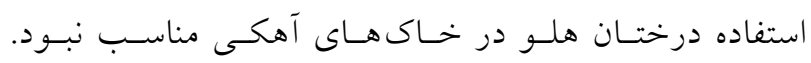

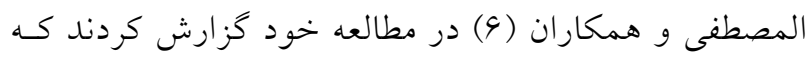

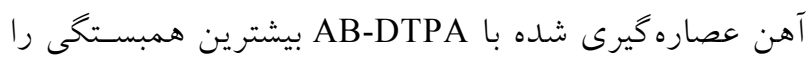

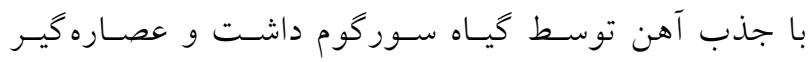
AB-DTPA

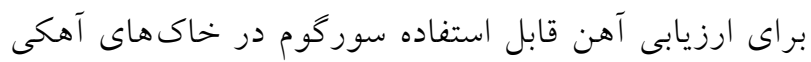

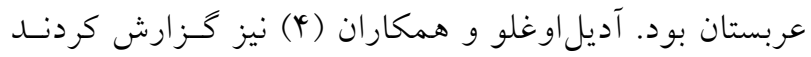

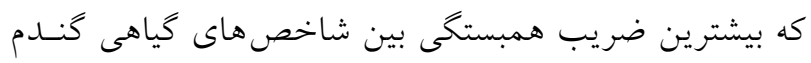

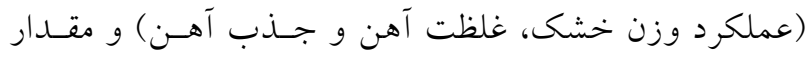

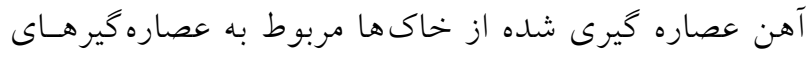

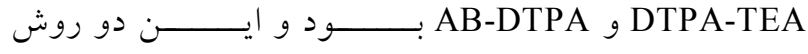
عصاره گيرى مناسبترين روشها براى ارزيابى وضعيت آهن قابل استفاده كُندم در خاكهاى آهكى تركيه بودند. 
جدول و. حد بحرانى آهن (ميلى گرم بر كيلوگرم) بر اساس معادله ميجرليخ با درنظر گرفتن عملكرد نسبى (هی درصد)

\begin{tabular}{|c|c|c|c|c|}
\hline مهليج r & مهليج r & DTPA-TEA & AB-DTPA & \\
\hline $1 / 00$ & $0 / 4 q$ & T/AI & $r / 9 \mathrm{~V}$ & مقدار حد بحرانى \\
\hline$\circ / V^{* *}$ & $\circ / 9^{* *}$ & $\circ / \Lambda Y^{* * *}$ & $\circ / \Lambda \varsigma^{* *}$ & ضريب تبيين (R) \\
\hline
\end{tabular}

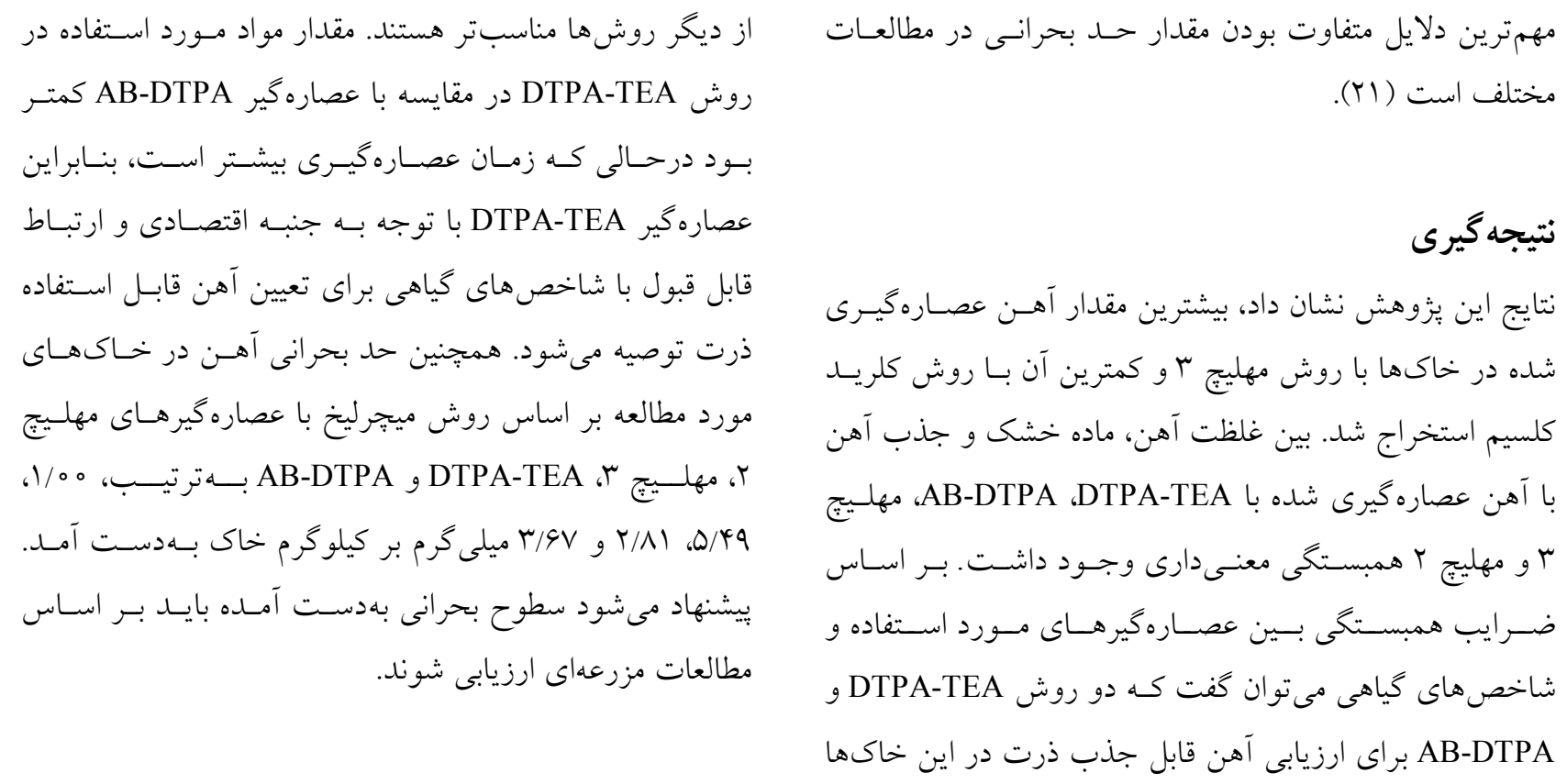

منابع مورد استفاده

1. Abdolahi, A., M. J. Malakouti and J. Ghaderi. 2011. Potassium fertilizer recommendations through determination of mitscherlich-bray equation coefficients for irrigated wheat Iranian. Journal of Soil and Water Research 42:121-128. (In Farsi).

2. Adiloglu, A. 2002. Determination of suitable chemical extraction methods for available iron content of the soils from Edirne province in Turkey. Journal of Central European Agriculture 3(3): 255-262.

3. Adiloglu, A. 2006. Determination of sutiable chemical extraction methods for available iron content of brown forest soils in Turkey. Eurasian Journal of Soil Science 39(9): 961-967.

4. Adiloglu, A., S. Adiloglu and M. R. Karaman. 2018. Determination of suitable extraction method for the available iron (Fe) content of calcareous soils. Turkish Journal of Agriculture - Food Science and Technology 6(1): 51-54.

5. Allowoy, B.J. 1990. Heavy Metals in Soils. Blackie and Son Ltd. Glascow and London.

6. Al-Mustafa, W., A. Abdallah and A. Falatah. 2001. Assessment of five extractants for their ability to predict iron uptake and response of sorghum grown in calcareous soils. Communications in Soil Science and Plant Analysis 32(5-6): 907-919.

7. Barbarick, K. A. and S. M. Workman. 1987. Ammonium Bicarbonate-DTPA and DTPA extractions of sludgeamended soils. Journal of Environment Quality 16(2): 125-130.

8. Brown, J. R., T.E. Bales and M. L. Vitosh. 1987. Soil Testing: Sampling, Correlation, Calibration and interpretation. Book series No. 21. Soil Science Society of America, Special pub., Madisson, WI., USA.

9. Campbell, C. R. and C. O. Plank 1998. Preparation of plant tissue for laboratory analysis. PP. 37-50. In: Kalra, Y. P. (Eds.), Handbook of Reference Methods for Plant Analysis, CRC Press, Taylor \& Francis Group. 
10. Celik, H. and A.V. Katkat. 2010. Comparison of various chemical extraction methods used for determination of the available iron amounts of calcareous soils. Communications in Soil Science and Plant Analysis 41: 290-300.

11. Elgala, M., A. S. Ismail and M. A. Ossman. 1986. Critical levels of iron, manganese and zinc in Egyptian soils. Journal of Plant Nutrition 9: 267-280.

12. Emami, M. and E. Dordipour. 2012. Selection of suitable extractant to extract available iron in peach in soils of Golestan Province. Journal of Soil Management and Sustainable Production 2(2):89-103. (In Farsi).

13. Eteng, E. U. and D. O. Asawalam. 2015. Evaluation of five extraction methods for predicting available forms of iron in soils of Southeastern, Nigeria. Journal of Agriculture and Veterinary Science 8: 2319-2370.

14. Farshi, A. A. and M. Mirlatifi. 2003. On-Farm Irrigation Water Management. Iranian National Committee on Irrigation and Drainage. (In Farsi).

15. Gee, G. H. and J. W. Bauder. 1986. Particle size analysis. PP. 383-409. In: Klute, A. (Eds.), Methods of Soil Analysis, Part 2, Physical Properties, SSSA, Madison, Wisconsin, USA.

16. Havlin, J. L. and P. N. Soltanpour. 1981. Evaluation of the $\mathrm{NH}_{4} \mathrm{HCO}_{3}-\mathrm{DTPA}$ soil test for iron and zinc. Soil Science Society of America Journal 45: 70-75.

17. Haynes, R. J. and R. S. Swift. 1983. An evaluation of the use of DTPA and EDTA as extractants for micronutrients in moderately acid soils. Plant and Soil 74: 111-122.

18. Hoyt, P. B. and M. Nyborg. 1971. Toxic metals in acid soil. 2. Estimation of plant available manganese. Soil Science Society of America Proceedings 35: 141-144.

19. Jafari, M. and F. Sarmadian. 2008. Fundamental of Soil Science and Soil Taxonomy. University of Tehran Press. (In Farsi).

20. Khalkhal, K., A. Reyhanitabar and N. Najafi. 2016. Evaluation of some extraction for determination of corn available iron in some soils of East Azerbaijan Province. Iranian Journal of Soil and Water Research 47(2): 427437. (In Farsi).

21. Khodshenas, M. A., J. Ghadbeiklou and M. Dadivar. 2017. Critical level of iron for bean (Phaseolus vulgaris L.) cultivation in Markazi Province. Journal of Water and Soil 31(4): 1148-1158. (In Farsi).

22. Knezek, B. D. and B. Ellis. 1980. Essential micronutrients, IV. Copper, iron, manganese and zinc. PP. 259-286. In: Davies, B. E. (Eds.), Applied Trace Elements. Wiley, New York.

23. Lindsay W. L. and W. A. Norvell. 1978. Development of a DTPA soil test for zinc, iron, manganese, and copper. Soil Science Society of America Journal 42: 421-428.

24. Lindsay, W. L. 1979. Chemical Equilibria in Soils, John Wiley \& Sons, NewYork.

25. Lindsay, W. L., and A. P. Schwab. 1982. The chemistry of iron in soils and its availablility to plants. Journal of Plant Nutrition 5: 821-840.

26. Loeppert, R. H. and D. L. Sparks. 1996. Carbonate and gypsum. PP. 437-474. In: Sparks, D. L. (Eds.), Methods of Soil Analysis, Part 3, Chemical Methods, SSSA, Madison, Wisconsin, USA.

27. Mahashabde, J. P. and S. Patel. 2012. DTPA-Extractable micronutrients and fertility status of soil in Shirpur Tahasil region. International Journal of ChemTech Research 4: 1681-1685.

28. Malakouti, M. J., and M. M. Tehrani. 1999. Role of microelements on yield and quality of agricultural productions. Tarbiat Modares Publication, Tehran. Iran. (In Farsi).

29. Malakouti, M. J. and M. N. Gheibi. 1999. Determination of Critical Levels of Nutrients in Soil, Plant, and Fruit for the Quality and Yield Improvements in Strategic Crops of Iran. High Concoil for Appropriate Use of Pesticides and Chemical Fertilizers, Ministry of Agriculture. Karaj. Iran. (In Farsi).

30. Mehlich, A. 1978. New extractant for soil test evaluation of phosphorus, potassium, calcium, magnesium, sodium, manganese and zinc. Communications in Soil Science and Plant Analysis 9: 477-492.

31. Mehlich, A. 1984. Mehlich 3 soil test extractant: A modification of Mehlich 2 extractant. Communications in Soil Science and Plant Analysis 15: 1409-1416.

32. Motaghian, H. R. and A. Hosseinpour. 2013. Assessment of several extractants for the determination of zinc bioavailability to bean (Phaseolus vulgaris L.) in calcareous soils amended and unamended with sewage sludge. Journal of Water and Soil 27(4): 742-752. (In Farsi).

33. Nabavi Moghadam, R., M. H. Saberi and M. H. Sayyari. 2013. Effect of soil application of iron and manganese sulfate on quantitative and qualitative characteristics of forage maize Hybrid Single Cross 704. Journal of Agricultural Crops Production 15(2): 75-86. (In Farsi).

34. Nelson, D. W. and L. E. Sommers. 1996. Total carbon organic carbon and organic matter. PP. 961-1011. In: Sparks, D. L. (Eds.), Methods of Soil Analysis, Part 3, Chemical Methods, SSSA, Madison, Wisconsin, USA.

35. Olsen, S. R., C. V. Cole, F. S. Watanabe and L. A. Dean. 1954. Estimation of Available Phosphorus in Soils by Extraction with Sodium Bicarbonate. Circular, 939 (p. 19). Washington, DC: US Department of Agriculture.

36. Rhoades, J. D. 1996. Salinity, electrical conductivity and total dissolved solids. PP. 417-437. In: Sparks, D. L. (Eds.), Methods of Soil Analysis, Part 3, Chemical Methods, SSSA, Madison, Wisconsin, USA. 
37. Sahuquillo, A., A. Rigol and G. Rauret. 2003. Overview of the use of leaching/extraction tests for risk assessment of trace metals in contaminated soils and sediments. Trends in Analytical Chemistry 22: 152-159.

38. Santiago, de A. and A. Delgado 2006. Predicting iron chlorosis of lupin in calcareouse Spanish soils from iron extracts. Soil Science Society of America Journal 70: 1945-1950.

39. Soltanpour, P. N., and A. P. Schwab. 1977. A new soil test for simultaneous extraction of macro and micronutrients in alkaline soils. Communications in Soil Science and Plant Analysis 8: 195-207.

40. Sumner, M. E. and W. P. Miller. 1996. Cation exchange capacity and exchange coefficient. PP. 1201-1229. In: Sparks, D. L. (Ed.), Methods of Soil Analysis, Part 3, Chemical Methods, SSSA, Madison, Wisconsin, USA.

41. Thomas, G. W. 1996. Soil pH and soil acidity. PP. 475-491. In: Sparks D. L. (Eds.), Methods of Soil Analysis, Part 3, Chemical Methods, SSSA, Madison, Wisconsin, USA. 


\title{
Assessment of Several Extractants for the Determination of Fe Availability to Corn (Zea mays L.) and its Critical Level in Some Calcareous Soils
}

\author{
H. Motaghian*, M. Shirmohammadi and A. Hosseinpur ${ }^{1}$
}

(Received: April 5-2020; Accepted: February 28-2021)

\begin{abstract}
Iron $(\mathrm{Fe})$ is an essential micronutrient for plants and its deficiency occurs in calcareous soils. However, a suitable extractant for the estimation of plant-available $\mathrm{Fe}$ and its critical level in calcareous soils depends on the type of soil and plant. The objective of the present study was to evaluate several chemical extractants to estimate available $\mathrm{Fe}$ and its critical level for corn growing in calcareous soils from Chaharmahal-Va-Bakhtiari Province. The amount of available Fe was measured by DTPA-TEA, AB-DTPA, $0.01 \mathrm{M}$ calcium chloride, Mehlich II, and Mehlich III extractants. At the end of the experiment, corn was harvested, and dry weight, Fe concentration in the plant, and the amount of Fe uptake by corn were determined. Extracted Fe had a significant correlation with all extractants used with maize indices. . The highest correlation coefficients were determined between the DTPA-TEA (0.32-0.94) and AB-DTPA (0.43-0.96) methods and the plant indices. The results of this research showed that the DTPA-TEA and AB-DTPA methods were the most suitable extractants for predicting available Fe content in these soils and the critical level of Fe extracted by these extractants was 2.81 and $3.67 \mathrm{mg} \mathrm{kg}^{-1}$.
\end{abstract}

Keywords: Available Fe, Criticlal level, Corn, Soil chemical extractants

1. Soil Science Department, Shahrekord University, Chaharmahal-Va-Bakhtiari, Iran. Corresponding author, Email: Motaghian.h@yahoo.com 